\title{
ASSESSMENT OF LEVEL OF ALCOHOL DEPENDENCE AND QUALITY OF LIFE AMONG ALCOHOLICS IN SELECTED RURAL COMMUNITIES, TAMILNADU
}

\author{
DINESH SELVAM S ${ }^{1} \&$ S.KANCHANA ${ }^{2}$ \\ ${ }^{1}$ Principal, Columbia College of Nursing, Bengaluru, Karnataka, India \\ ${ }^{2}$ Principal, Omayal Achi College of Nursing, Chennai, Tamil Nadu, India
}

\begin{abstract}
Alcohol has now become a common word in Indian society. Alcohol abuse/dependence is a serious clinical condition, signifying a major impairment in the dependent individual's quality of life (QOL) in conjunction with the severity of alcohol misuse. The objectives of the study was to assess the level of alcohol dependence and level of Quality of Life among alcoholics, to correlate between the level of alcohol dependence and Quality of Life and to associate the level of alcohol dependence and quality of life among alcoholics with their demographic variables. Total Enumeration of all the alcoholics identified as clinically significant in the rural villages were considered as sample. Descriptive survey method was used to assess the level of alcohol dependence and level of quality of life among alcoholics. The study findings revealed that $23.73 \%$ of the male population was clinically significant alcoholics. The mean percentage for overall alcohol dependence was $40 \%$ and for overall Quality of Life was $49 \%$. The study interpreted that majority of them had moderate Quality of Life and it was related to the level of alcohol dependence. A strong community based interventions were necessary to improve the Quality of life and reduce the level of alcohol dependence among alcoholics.
\end{abstract}

KEYWORDS: Alcohol dependence, Quality of Life \& Alcoholics.

Received: Jun 04, 2021; Accepted: Jun 24, 2021; Published: Jul 02, 2021; Paper Id.: IJMPSDEC20214

\section{INTRODUCTION}

According to (WHO) estimates, there are about 2 billion people worldwide who consume alcoholic beverages and 76.3 million with diagnosable alcohol-use disorders. In India, per capita consumption of alcoholic beverages equaled 2.59 litres of pure alcohol consumed by every person aged 15 years or older the unrecorded consumption and expenditure on alcohol still remains high in India. Changing social norms, urbanization, increased availability, high intensity mass marketing and relaxation of overseas trade rules along with poor level of awareness related to alcohol has contributed to increased alcohol use. The emerging trends include initiation of drinking at an early age, greater consumption among women, greater permeation in rural and peri-urban areas, increasing preference for drinks with high alcohol content, and hazardous and harmful drinking.

Alcohol dependence means the person is physically dependent on alcohol. Alcohol dependence is a chronic disorder. If a complete cure of the disorder is generally not possible, long-term supervision of alcohol dependence is required in order to ensure that alcohol-dependent patients have the best possible state of general health. The World Health Organization has defined health not only as the absence of disease but also as a state of physical, mental and social well-being. The idea of quality of life (QOL) incorporates these dimensions and can be defined as "an individual's perception of their position in life, and in the context of the culture and value systems in which they live, and in relation to their goals, expectations, standards and concerns. 
QOL, which is a concept situated between social and clinical sciences, is a pertinent indicator to evaluate the subjective experience of the alcoholics and to quantify the psychosocial burden of alcoholism. In quality of life research, the aim is to measure the alcoholics' subjective perception of their state of health and life using a standardized questionnaire.

Alcohol abuse/dependence is a serious clinical condition, signifying a major impairment in the dependent individual's quality of life (QOL) in conjunction with the severity of alcohol misuse. As indicated by accumulated research evidence and clinical observation, alcohol dependence is characterized by a high degree of deterioration in physical health, psychological well-being and social life. In any case, the detrimental effects of alcohol consumption are usually observable in several aspects of everyday life, including sleep, mobility, energy, somatic pain, interpersonal and social relations, areas that are frequently reported by alcohol-dependent patients to relate to QOL deterioration. The relationship between these QOL determinants and relapse and remission, is an intriguing issue that deserves to be examined in alcoholic populations. Furthermore, factors such as patient characteristics or clinical variables like symptomatology and comorbidity are also important to be examined in relation to QOL and treatment outcomes. To date, there is sufficient evidence that alcohol dependent individuals experience a serious reduction in QOL related to alcohol consumption.

WHO's aim is to reduce the health burden caused by the harmful use of alcohol and, thereby, to save lives, prevent injuries and diseases and improve the Quality of Life of individuals, communities and society at large. WHO emphasizes the development, creating, compiling and disseminating scientific information on alcohol use and dependence, and related health and social consequences.

The objectives of the study were 1) to identify the clinically significant alcoholics 2) to assess the level of alcohol dependence and level of Quality of Life among alcoholics 3) to correlate between the level of alcohol dependence and Quality of Life 4) to associate the level of alcohol dependence and Quality of Life of alcoholics with their demographic variables.

\section{METHODS}

The researcher used Quantitative Research Approach and Descriptive Survey Approach for the study. The Background variables of the study were Age, Education status, Occupation, Annual Income per month, Marital status, Religion, Type of family, Number of family members, Food habits, any History of medical history, Duration of alcoholism, How many times per week, and Undergone any treatment for alcoholism. The study variables were Level of Alcohol dependence and Quality of Life among alcoholics. The setting of the study was the 5 adopted rural villages of Omayal Achi Health Center which identified to have alcohol dependence as a common problem through village survey conducted by Omayal Achi Community Health Center. Clinically significant alcoholics of the adopted rural villages of Omayal Achi Health Center who fulfill the inclusion criteria were the samples of the study. The sample size comprised of total estimated 473 alcoholics from the selected 5 rural villages of Omayal Achi Health Center.

Clinically Significant Alcoholics were identified through CAGE Questionnaire. Level of dependence among Alcoholics was assessed using SADQ-C (Severity of Alcohol Dependence Quotient - Community). Quality of Life among Alcoholics was assessed through modified WHO QOL BREF 26 item index modified tool which had 4 dimensions like Physical, Psychological, Social and Environmental domains. The investigator considered and followed the ethical principles preceding the investigation. 


\section{RESULTS AND DISCUSSIONS}

Totally, 473 Alcoholics were identified as clinically significant in the adopted rural communities. The findings revealed that about $23.73 \%$ of male population were identified as clinically significant alcoholics. This finding was supported by the National household survey of alcohol and drug abuse which reported $21.4 \%$ to be alcoholics.

Majority 191(40.6\%) of the alcoholic dependents were in the age group between 41-50 years; 418(88.4\%) of them were married; 427(90.4\%) of them belong to Hindu religion; 344(72.7\%) of them belong to nuclear family; 328(69.3\%) of them had 3-4 family members; 417(88.2\%) were non-vegetarians; 446(94.3\%) of them had no history of medical illness; 470(99.4\%) of them had not undergone any treatment for alcoholism. 186(39.3\%) of them had primary education; $166(35.1 \%)$ of them were semi-skilled workers; $169(35.7 \%)$ of them had income of Rs.4000-6000; 212(44.8\%) of them had the habit of alcoholism for 4-6 years; 83(17.6\%) of them had alcohol 3 times per week.

Findings revealed that with regard to frequency and percentage distribution of level of alcohol dependence among alcoholics, out of 473 alcoholics, 182(38.6\%) of them had mild level of alcohol dependence and scored between 4-19 in SADQ. 165(34.9\%) of them had moderate level of alcohol dependence and scored between 20-30 in SADQ. 94(19.8\%) of them had severe level of alcohol dependence and scored between 31-44 in SADQ. 32(6.7\%) of them had very severe level of alcohol dependence and scored between 44- 60 in SADQ (Table 1). The overall mean score of level of alcohol dependence was 24.15 with standard deviation of 11.65 and mean $\%$ of 40 . These descriptions reveal that although majority of them had mild and moderate level of alcohol dependence, considerable number of them had severe and very severe level of alcohol dependence.

Table 2: Mean, SD and Mean\% of Quality of Life (Domain wise) among Alcoholics N=473

\begin{tabular}{|l|l|c|}
\hline \multirow{2}{*}{ Level of Alcohol Dependence } & \multicolumn{2}{|c|}{ Pre-test } \\
\cline { 2 - 3 } & No. & \% \\
\hline Mild & 182 & 38.6 \\
\hline Moderate & 165 & 34.9 \\
\hline Severe & 94 & 19.8 \\
\hline Very severe & 32 & 06.7 \\
\hline
\end{tabular}

With regard to the level of Quality of Life in 4 domains: Physical health (Domain I), Psychological Health (Domain II), Social Relationship (Domain III) and Environment Health (Domain IV), Majority of them had moderate quality of life i.e. 303 (64\%) in Domain I, 261(55\%) in Domain II, 211(45\%) in Domain III, and 282(59.6\%) in Domain IV respectively. Relatively, more number of alcoholics had low quality of life i.e., 127(27\%) in Domain I, 165(35\%) in Domain II, 205 (43\%) in Domain III and 136(28.8\%) in Domain IV respectively. Considerable Number of alcoholics had high quality of life i.e., 42(8.8\%) in Domain I, 38(8.1\%) in Domain II, 50(10.5\%) in Domain III and 51(10.8\%) in Domain IV. Relatively less number of alcoholics had very low quality of life i.e., 1(0.2\%) in Domain I, 9(1.9\%) in Domain II, 7 (1.5\%) in Domain III and 4(0.8\%) in Domain IV. Regarding Overall Quality of Life, majority of alcoholics 311(65.8\%) had moderate quality of life, $111(23.4 \%)$ had low quality of life and 51 (10.8\%) had high quality of life none of them had very low quality of Life. Regarding overall Quality of Life, the pre-test mean was 194.80 and SD was 73.02 with mean \% of 49. 


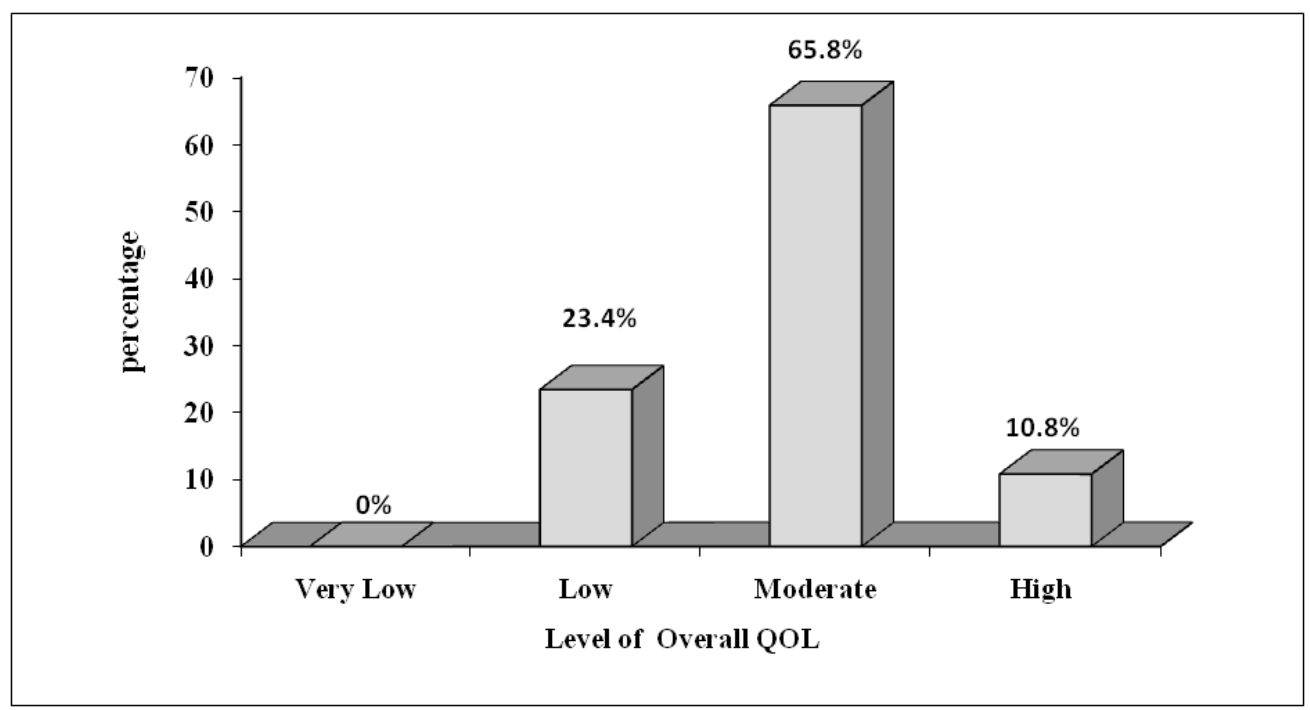

Figure 1: Frequency and Percentage distribution of level of Overall Quality of Life among Alcoholics

Table 2: Mean, SD and Mean\% of Quality of Life (Domain wise) among Alcoholics N=473

\begin{tabular}{|l|c|c|c|c|c|c|c|}
\hline \multirow{2}{*}{$\begin{array}{c}\text { Quality of Life } \\
\text { Domains }\end{array}$} & \multirow{2}{*}{$\begin{array}{c}\text { Max } \\
\text { score }\end{array}$} & \multicolumn{3}{c|}{ Pre test scores } & \multicolumn{3}{c|}{ Post test scores } \\
\cline { 5 - 9 } & Mean & SD & Mean\% & Mean & SD & Mean\% \\
\hline $\begin{array}{l}\text { Physical Health } \\
\text { (Domain I) }\end{array}$ & 100 & 49.32 & 18.69 & 49 & 54.56 & 16.74 & 55 \\
\hline Psychological Health (Domain II) & 100 & 48.03 & 18.99 & 48 & 53.74 & 17.98 & 54 \\
\hline Social Relationship (Domain III) & 100 & 49.12 & 21.44 & 49 & 57.49 & 20.86 & 58 \\
\hline Environmental Health (Domain IV) & 100 & 48.33 & 19.23 & 48 & 52.91 & 18.32 & 53 \\
\hline Overall QOL & 400 & 194.803 & 73.02 & 49 & 218.73 & 68.32 & 56 \\
\hline
\end{tabular}

The analysis revealed that there was significant negative correlation between Level of Alcohol Dependence in all domains and Quality of Life among Alcoholics thereby interpreting that as the Level of alcohol dependence reduces the Quality of Life among Alcoholics improves. (Fig.2)

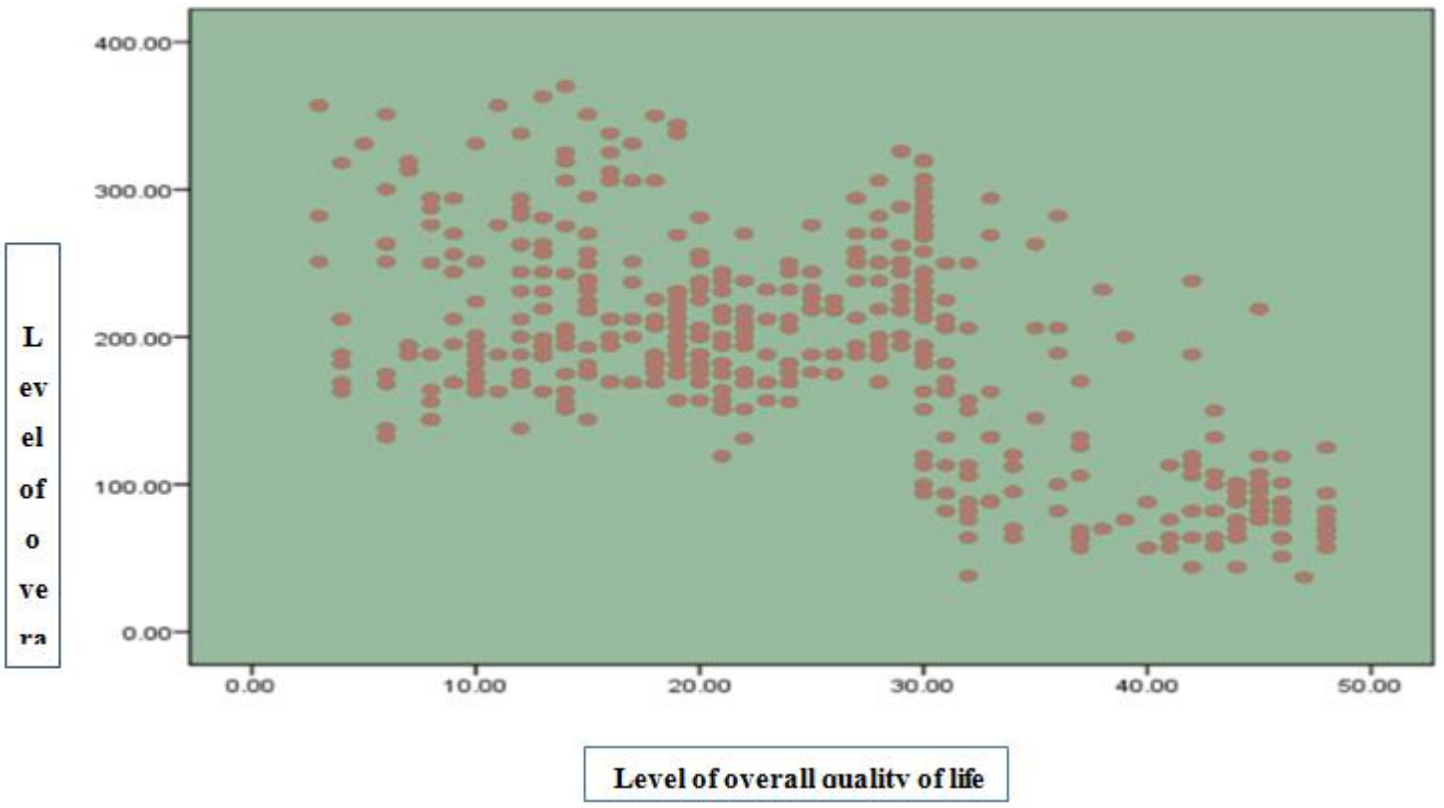

Figure 2: Frequency and Percentage distribution of level of Overall Quality of Life among Alcoholics 
There was significant association of the level of alcohol dependence with the occupation and number of times of alcohol intake among Alcoholics. There was a significant association of Quality of Life between occupation, income and duration of alcoholism.

\section{CONCLUSIONS}

The clinically significant alcoholics were $23.73 \%$ correlates with the National Household Survey findings. The level of alcohol dependence was highly significant among alcoholics. The Quality of Life was moderate and was related to level of dependence among alcoholics. The level of dependence increases, the quality of life decreases among alcoholics. The nurse-led screening, community based interventions are required to reduce the level of alcohol dependence and thereby to improve the Quality of Life among alcoholics.

\section{ACKNOWLEDGEMENTS}

Author is grateful to Omayal Achi Community Health Center and International Collaborative Center for Research for providing permission and guidance to carry out this research work.

\section{REFERENCES}

1. World Health Organization. (2011). Global status report on alcohol and health. World Health Organization

2. Clecia Nunes Bezerra, Rodrigo Rebouças De Castro \& Flávio Soares Araújo, "Women in Treatment for Alcoholism in a Brazilian State Capital: Socio-Demographic Characteristics", International Journal of Medicine and Pharmaceutical Science (IJMPS) ,Vol. 9, Issue 4,pp, 57-62

3. Gururaj G, et al. (2011). Alcohol related harm: Implications for public health and policy in India, 73.

4. Anita Sharma, "The Role of Parent-Child Relationship in the Development of Alcoholism", International Journal of Human Resource Management and Research (IJHRMR), Vol. 8, Issue 6,pp, 45-52

5. American Public Health Association and Education Development Center (2008). Alcohol screening and brief intervention: A guide for public health practitioners. Washington DC.

6. Pierre Lahmek, et al. (2009). Determinants of improvement in quality of life of alcohol-dependent patients during an inpatient withdrawal programme. International Journal of Medical Science, 6,160-167.

7. Vipin John Vincent, Paul Anto, Nisha Sherief \& Kevin Jose, "Experimental Investigation to Control Alcoholic Driving", IMPACT: International Journal of Research in Engineering \& Technology (IMPACT: IJRET), Vol. 2, Issue 4, pp, 123-128

8. Ministry of Social Justice and Empowerment (2005). Developing community Drug Rehabilitation. New Delhi.

9. Alcohol. Fact sheet (2011) retrieved from http://www.who.int/mediacentre/ factsheets/fs349/en/

10. Ewing, J.A. Detecting alcoholism: The CAGE questionnaire. Journal of the American medical association. 252, 1905-1907

11. Tim Stockwell, et al. The Development of a Questionnaire to Measure Severity of Alcohol Dependence. British Journal of Addiction to Alcohol \& Other Drugs. 1979, 74(1), 79-87.

12. Russell J. Zwanka, "Does Beer can Shape and Size Influence Health Perception of Contents?", IMPACT: International Journal of Research in Business Management (IMPACT: IJRBM), Vol. 8, Issue 1, pp, 1-14

13. WHO. WHOQOL-BREF Introduction, Administration, Scoring and Generic version of the assessment. Geneva. 
